\title{
Excretion of individual adrenocortical steroids in obese children
}

\author{
D. C. L. SAVAGE, CONSTANCE C. FORSYTH, and JENNY CAMERON \\ From the Department of Child Health, University of Dundee, and Ninewells Hospital, Dundee, Scotland
}

\begin{abstract}
Savage, D. C. L., Forsyth, C. C., and Cameron, J. (1974). Archives of Disease in Childhood, 49, 946. Excretion of individual adrenocortical steroids in obese children. The excretion of 13 individual adrenocortical metabolites in the urine of 21 obese children aged 7 months to 16 years is reported. Fractionation of the steroids was carried out on 24-hour samples of urine by paper chromatography using Bush systems and incorporating a radioactive steroid recovery technique. The excretion of the 17-hydroxycorticosteroids and of the $\alpha$-ketolic metabolites of cortisol and corticosterone exceeded that of normal children studied in the same manner. These differences persisted when the results were corrected for surface area but were eliminated by correction for body weight. The raised corticosteroid excretion in obese children is therefore related to the increased weight. In addition the excessive calorie intake enhances the hepatic metabolism of cortisol leading to an increased corticosteroid excretion.

The excretion of the 17-oxosteroids and 11-deoxygenated-17-oxosteroids exceeded that of normal children. Before puberty these steroids represent the adrenal androgens, and the raised excretion in the obese children was associated with an advanced bone age. The early onset of puberty in obesity may be related to the increased body weight, but it is suggested that the increased adrenal androgen secretion may stimulate early maturation of the hypothalamic centre controlling the onset of puberty.
\end{abstract}

Simple obesity is associated with generalized metabolic and endocrine abnormalities which include a disturbance of body composition, disordered carbohydrate and lipid metabolism, insulin resistance, and anomalies of growth hormone secretion and adrenocortical function (Albrink, 1968; Gordon, 1970; Salans and Wise, 1970).

Though there are a number of reports on adrenocortical function in childhood obesity, these have examined only the total 17-oxosteroids and 17-hydroxycorticosteroids or a few individual metabolites (Simpson, 1953; Gray et al., 1956; Cohen, 1958; Migeon, Green, and Eckert, 1963; Jacobson et al., 1964; Van Herle et al., 1967; Garces et al., 1968). The present study gives a more comprehensive picture as it details the excretion of 13 individual adrenocortical metabolites in the urine of obese children and correlates them with the child's weight and surface area, the degree of obesity, and the skeletal and sexual maturity.

Received 26 April 1974.

\section{Subjects and methods}

There were 21 children included in this study and their ages ranged from 7 months to 16 years 3 months. The degree of obesity was calculated as the percentage above their ideal body weight for their sex and height age, using the Tanner and Whitehouse (1966) growth chart. The bone age was calculated according to the tables of Tanner, Whitehouse, and Healy (1962).

Fractionation of the adrenocortical steroid metabolites was carried out as described previously (Savage et al., 1974). Two pooled 24-hour urine samples were used in the younger children and a single 24-hour specimen in the older children. After extraction and hydrolysis of the steroid conjugates both glucuronide and sulphate fractions were assayed separately, final separation of the individual steroids being carried out by paper chromatography using Bush systems. Any free steroid present initially was assayed with the glucuronide fraction. Radioactive steroids were added to each urine specimen immediately before assay and were used to correct for losses incurred during the method. After staining with blue tetrazolium or Zimmermann reagent the individual steroids were quantitated by comparison with their respective standards using a photoelectric scanner. 
Table I gives details of the steroids assayed with their trivial names and abbreviations.

\section{TABLE I}

Adrenocortical steroids assayed and their trivial names and abbreviations

11-Deoxygenated 17-oxosteroids

Dehydroepiandrosterone or DHA for $3 \beta$-hydroxy-androst-5-en-

17-one; Aetiocholanolone or Aetio for $3 \alpha$-hydroxy-5 $\beta$ -

androstan-17-one; Androsterone or Andro for $3 \alpha$-hydroxy-5 $\alpha$ -

androstan-17-one

11-Oxygenated 17-oxosteroids

$11 \beta$-hydroxy aetiocholanolone or $11 \mathrm{OH}$ Aetio for $3 \alpha, 11 \beta$ dihydroxy-5 $\beta$-androstan-17-one; $11 \beta$-hydroxy androsterone or $11 \mathrm{OH}$ Andro for $3 \alpha, 11 \beta$-dihydroxy-5 $\alpha$-androstan-17-one; 11-Oxo aetiocholanolone or 110 Aetio for $3 \alpha$-hydroxy-5 $\beta$ androstan-11, 17-dione; 11-Oxo androsterone or $11 \mathrm{O}$ Andro for $3 \alpha$-hydroxy-5 $\alpha$-androstan-11, 17-dione

Cortisol $\alpha$-ketolic metabolites

Tetrahydrocortisol or THF for $3 \alpha, 11 \beta, 17 \alpha, 21$-tetrahydroxy$5 \beta$-pregnan-20-one; allo-Tetrahydrocortisol or allo-THF for $3 \alpha, 11 \beta, 17 \alpha, 21$-tetrahydroxy-5 $\alpha$-pregnan-20-one; Tetrahydrocortisone or THE for $3 \alpha, 17 \alpha, 21$-trihydroxy-5 $\beta$-pregnan-11 20-dione

Corticosterone $\alpha$-ketolic metabolites

Tetrahydrocorticosterone or THB for $3 \alpha, 11 \beta, 21$-trihydroxy$5 \beta$-pregnan-20-one; allo-Tetrahydrocorticosterone or allo-THB for $3 \alpha, 11 \beta, 21$-trihydroxy-5 $\alpha$-pregnan-20-one; Tetrahydro-11dehydrocorticosterone or THA for $3 \alpha, 21$-dihydroxy-5 $\beta$ pregnan-11, 20-dione

\section{Results}

In Fig. 1-5 the results are shown in comparison with the mean $\pm 2 \mathrm{SD}$ of the values for the normal children (Savage et al., 1974). The individual values for the obese children were evaluated statistically by their difference from the mean of normal children of the same age using Student's ' $t$ ' test (Savage et al., 1974). The children's percentage overweight ranged between $23 \%$ and $98 \%$ with a mean of $54 \%$. When the child's obesity began before school age it was regarded as of early onset; no correlation was found between the degree of obesity and the age of onset. The height in two-thirds of the children was greater than the 75 th centile, but in 3 of the older children it was below the 50th centile. In 19 of the children skeletal age was advanced. Individual results for each child are listed in Tables II, III, and IV.

17-Hydroxycorticosteroids. The excretion of the 17-hydroxycorticosteroids (17 OHCS) in many of the obese children was more than $2 \mathrm{SD}$ above the mean of the normal values, and the mean excretion of the group of obese children exceeded that of the normal children $(P<0 \cdot 001)$ (Fig. 1).

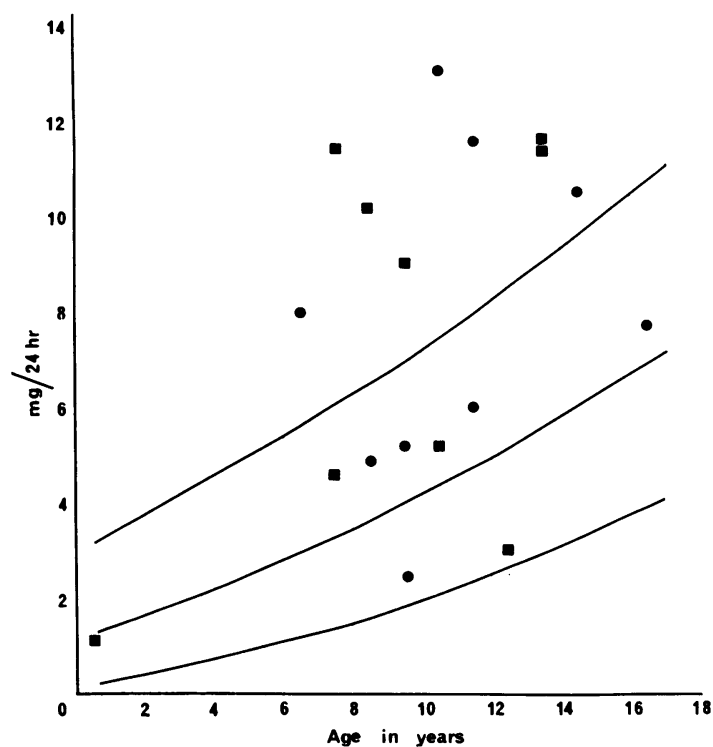

FIG. 1.-Excretion of 17-hydroxycorticosteroids in obese children plotted against the mean $\pm 2 S D$ of values for normal children. Girls $\mathbf{0}$, boys $\mathbf{\square}$.

$\alpha$-Ketolic cortisol metabolites. The excretion of the $\alpha$-ketolic cortisol metabolites in over half fof the obese children was more than $2 \mathrm{SD}$ above the mean of the normal values, and their mean excretion was significantly greater $(\mathbf{P}<0 \cdot 001)$ (Fig. 2). The pattern of excretion of these metabolites, with the exception of the increase in the $5 \alpha: 5 \beta$ ratio of allo-THF to THF (Table V) was no different to that of the normal children.

$\alpha$-Ketolic corticosterone metabolites. The mean excretion of the $\alpha$-ketolic metabolites of corticosterone exceeded the normal values ( $P<0.05$ ) (Fig. 4). The individual $\alpha$-ketolic corticosterone metabolites showed a similar pattern to that of normal children and allo-THB was consistently the major steroid excreted.

Corticosteroid excretion corrected for body size. When corrected for surface area, both the mean 17 OHCS (Fig. 3) and the mean $\alpha$-ketolic cortisol metabolite excretion in the obese children exceeded that of the normal children $(P<0.05)$. However, when corrected for body weight only one obese child lay over $2 \mathrm{SD}$ above the normal values, and taken as a group the obese children were not different from the normal children. The excretion of the $\alpha$-ketolic corticosterone metabolites in the obese children was not significantly greater than that of the normal children when corrected for surface area or for body weight. 
TABLE II

Details of individual obese children

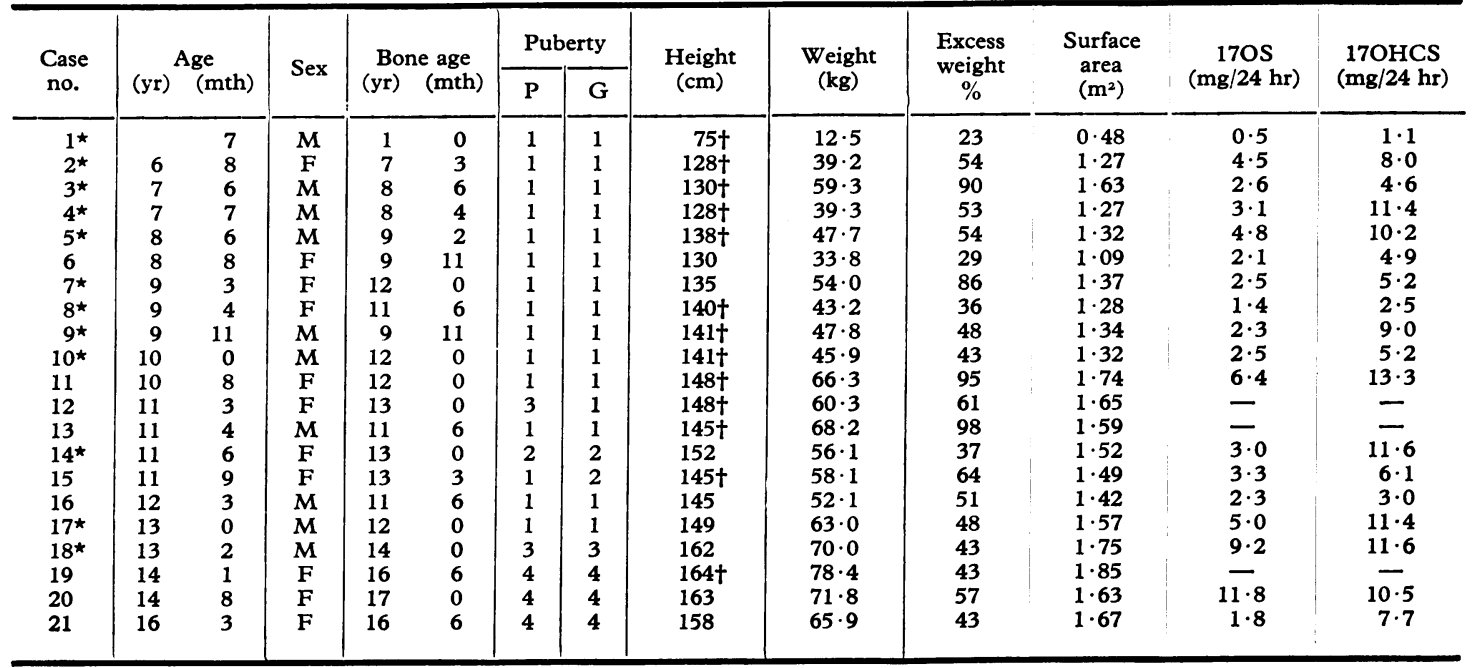

*Early onset of obesity.

tHeight $>75 \%$.

TABLE III

Individual results of corticosteroid excretion in obese children

\begin{tabular}{|c|c|c|c|c|c|c|c|c|}
\hline $\begin{array}{c}\text { Case } \\
\text { no. }\end{array}$ & THF & $\begin{array}{c}\text { allo } \\
\text { THF }\end{array}$ & THE & $\underset{\mathbf{F}}{\alpha} \underset{\text { ketolic }}{\alpha}$ & ТНВ & $\begin{array}{c}\text { allo } \\
\text { THB }\end{array}$ & THA & $\begin{array}{c}\alpha \\
\text { ketolic } \\
\mathbf{B}\end{array}$ \\
\hline $\begin{array}{r}1 \\
2 \\
3 \\
4 \\
5 \\
6 \\
7 \\
8 \\
9 \\
10 \\
11 \\
12 \\
13 \\
14 \\
15 \\
16 \\
17 \\
18 \\
19 \\
20 \\
21\end{array}$ & $\begin{array}{r}454 \\
640 \\
1210 \\
1313 \\
2029 \\
433 \\
1725 \\
292 \\
2160 \\
502 \\
1535 \\
1218 \\
2603 \\
1325 \\
1247 \\
915 \\
990 \\
2018 \\
1728 \\
1277 \\
-\end{array}$ & $\begin{array}{r}684 \\
1133 \\
806 \\
2469 \\
2438 \\
985 \\
2323 \\
745 \\
965 \\
1004 \\
2038 \\
2183 \\
3098 \\
2556 \\
1514 \\
635 \\
1289 \\
3278 \\
2487 \\
1261 \\
-\end{array}$ & $\begin{array}{r}349 \\
1512 \\
503 \\
2621 \\
1611 \\
798 \\
979 \\
320 \\
3358 \\
1027 \\
2317 \\
1634 \\
2084 \\
1099 \\
1147 \\
502 \\
2084 \\
2653 \\
1606 \\
1310 \\
-\end{array}$ & $\begin{array}{c}1487 \\
3285 \\
2519 \\
6403 \\
6078 \\
2216 \\
5027 \\
1357 \\
6483 \\
2533 \\
5890 \\
5035 \\
7785 \\
4980 \\
3908 \\
2052 \\
4363 \\
7949 \\
5821 \\
3848 \\
-\end{array}$ & $\begin{array}{r}- \\
54 \\
\overline{203} \\
25 \\
68 \\
16 \\
113 \\
43 \\
13 \\
17 \\
40 \\
41 \\
116 \\
94 \\
13 \\
91 \\
19 \\
83 \\
12\end{array}$ & $\begin{array}{r}- \\
\overline{152} \\
\overline{1} \\
1032 \\
226 \\
302 \\
75 \\
120 \\
351 \\
36 \\
128 \\
669 \\
128 \\
239 \\
99 \\
129 \\
545 \\
188 \\
283 \\
203\end{array}$ & $\begin{array}{r}- \\
14 \\
112 \\
24 \\
15 \\
14 \\
51 \\
17 \\
7 \\
25 \\
24 \\
11 \\
57 \\
54 \\
12 \\
176 \\
26 \\
47 \\
14\end{array}$ & $\begin{array}{r}\overline{2} \\
220 \\
220 \\
232 \\
1347 \\
275 \\
385 \\
105 \\
284 \\
411 \\
56 \\
170 \\
733 \\
180 \\
412 \\
247 \\
154 \\
812 \\
233 \\
413 \\
229\end{array}$ \\
\hline
\end{tabular}

Correlation of corticosteroid excretion with the degree of obesity. There was no correlation between the children's degree of obesity and their excretion of 17 OHCS, or $\alpha$-ketolic metabolites of cortisol or corticosterone corrected for body weight. 17-Oxosteroids. The excretion of the 17- This was seen at all ages including a markedly

$$
\text { children }(P<0.05) \text { (Fig. 5a). }
$$

11-Deoxygenated-17-oxosteroids. The excretion of the 11-deoxygenated-17-oxosteroids exceeded that of the normal children $(P<0.01)$. 
TABLE IV

Individual results of adrenal androgen excretion in obese children

\begin{tabular}{|c|c|c|c|c|c|c|c|c|c|}
\hline $\begin{array}{c}\text { Case } \\
\text { no. }\end{array}$ & DHA & Aetio & Andro & 11-Deoxy & $\begin{array}{c}\text { 11-OH } \\
\text { Aetio }\end{array}$ & $\begin{array}{l}\text { 11-OH } \\
\text { Andro }\end{array}$ & $\begin{array}{l}11-0 \\
\text { Aetio }\end{array}$ & $\begin{array}{c}11-0 \\
\text { Andro }\end{array}$ & 11-Oxy \\
\hline $\begin{array}{r}1 \\
2 \\
3 \\
4 \\
5 \\
6 \\
7 \\
8 \\
9 \\
10 \\
11 \\
12 \\
13 \\
14 \\
15 \\
16 \\
17 \\
18 \\
19 \\
20 \\
21\end{array}$ & $\begin{array}{r}0 \\
9 \\
34 \\
16 \\
14 \\
10 \\
14 \\
12 \\
25 \\
21 \\
11 \\
79 \\
13 \\
6 \\
16 \\
14 \\
50 \\
11 \\
221 \\
21\end{array}$ & $\begin{array}{r}0 \\
19 \\
207 \\
37 \\
285 \\
262 \\
169 \\
141 \\
- \\
141 \\
450 \\
155 \\
604 \\
586 \\
155 \\
334 \\
131 \\
383 \\
117 \\
426 \\
302\end{array}$ & $\begin{array}{r}13 \\
87 \\
191 \\
182 \\
378 \\
335 \\
178 \\
287 \\
314 \\
536 \\
347 \\
1243 \\
912 \\
182 \\
343 \\
153 \\
576 \\
208 \\
819 \\
400\end{array}$ & $\begin{array}{r}13 \\
115 \\
432 \\
235 \\
677 \\
607 \\
361 \\
440 \\
- \\
480 \\
1007 \\
513 \\
1926 \\
1511 \\
343 \\
693 \\
298 \\
1009 \\
336 \\
1466 \\
723\end{array}$ & $\begin{array}{r}16 \\
38 \\
127 \\
10 \\
244 \\
153 \\
214 \\
10 \\
97 \\
67 \\
299 \\
28 \\
317 \\
263 \\
73 \\
35 \\
152 \\
32 \\
31 \\
133 \\
85\end{array}$ & $\begin{array}{r}86 \\
51 \\
146 \\
38 \\
306 \\
213 \\
258 \\
70 \\
70 \\
71 \\
505 \\
89 \\
305 \\
432 \\
119 \\
121 \\
176 \\
354 \\
148 \\
326 \\
63\end{array}$ & $\begin{array}{r}108 \\
224 \\
592 \\
336 \\
532 \\
364 \\
470 \\
79 \\
297 \\
264 \\
648 \\
201 \\
839 \\
660 \\
288 \\
208 \\
232 \\
412 \\
167 \\
442 \\
250\end{array}$ & $\begin{array}{r}20 \\
18 \\
31 \\
26 \\
44 \\
23 \\
31 \\
5 \\
33 \\
11 \\
64 \\
7 \\
64 \\
126 \\
34 \\
8 \\
6 \\
41 \\
23 \\
46 \\
29\end{array}$ & $\begin{array}{r}230 \\
331 \\
896 \\
410 \\
1126 \\
753 \\
973 \\
164 \\
497 \\
413 \\
1516 \\
325 \\
1525 \\
1481 \\
514 \\
372 \\
566 \\
839 \\
369 \\
947 \\
427\end{array}$ \\
\hline
\end{tabular}

increased excretion of adrenal androgens in the urine of the prepubertal children aged 7-10 years (Fig. $5 b)$. When the results in the prepubertal children were plotted against skeletal age, the excretion of 11-deoxygenated-17-oxosteroids in some cases fell within the normal range.

11-Oxygenated-17-oxosteroids. The excretion of the 11-oxygenated-17-oxosteroids was in a quarter of the obese children greater than $2 \mathrm{SD}$ above that of the normal children, but for the obese group it was not significantly different from that of the normal children. Furthermore the pattern of excretion of the various 11-oxygenated metabolites, with the exception of an increase in their $5 \alpha: 5 \beta$ ratio (Table V), was similar to that of the normal children.

Ratio of $5 \alpha: 5 \beta$ urinary metabolites. The $5 \alpha: 5 \beta$ ratios for androsterone to aetiocholanolone,
$11 \beta$-hydroxy-androsterone to $11 \beta$-hydroxy-aetiocholanolone, the total $5 \alpha$ steroids of the 11-deoxy17-oxosteroids and 11-oxy-17-oxosteroids to the total $5 \beta$ steroids of the 11-deoxy-17-oxosteroids, and 11-oxy-17-oxosteroids and allo-THF to THF are listed in Table V. These ratios were higher than in normal children of the same age groups and the difference was particularly evident in those children whose skeletal maturity was more advanced.

11 - Deoxygenated - 17-oxosteroid:11oxygenated-17-oxosteroid ratio. This ratio was higher before and at puberty than in the normal children $(P<0 \cdot 01)$. Obese children $6-10$ years $0 \cdot 96,11-17$ years $1 \cdot 22$. Normal children $6-10$ years $0 \cdot 47,11-17$ years $0 \cdot 73$.

Ratio of corticosteroid: androgen excretion. The ratios of (a) the 17 OHCS to the 17 OS and (b)

TABLE V

The mean 5 $\alpha: 5 \beta$ ratios of individual adrenocortical steroids in obese children aged 6-10 years and 11-17 years

\begin{tabular}{|c|c|c|c|c|}
\hline Age group & Androsterone/aetiocholanolone & 11-OH-Andro/11-OH Aetio & $\begin{array}{c}\text { Total } 5 \alpha \text { 17-oxosteroids/total } 5 \beta \\
\text { 17-oxosteroids }\end{array}$ & Allo-THF/THF \\
\hline $\begin{array}{c}\text { 6-10 } \\
\text { P } \\
11-17 \\
P\end{array}$ & $\begin{array}{c}1 \cdot 7 \\
(1 \cdot 2) \\
\text { NS } \\
1 \cdot 6 \\
(1 \cdot 4) \\
\text { NS }\end{array}$ & $\begin{array}{c}2 \cdot 1 \\
(1 \cdot 6) \\
\text { NS } \\
3 \cdot 3 \\
(1 \cdot 7) \\
\text { NS }\end{array}$ & $\begin{array}{c}0.8 \\
(0.6) \\
\text { NS } \\
1.0 \\
(0.7) \\
<0.01\end{array}$ & $\begin{array}{c}1.5 \\
(0.7) \\
<0.01 \\
1.4 \\
(1.0) \\
<0.05\end{array}$ \\
\hline
\end{tabular}

Note: Mean figures for normal children are in parentheses. 


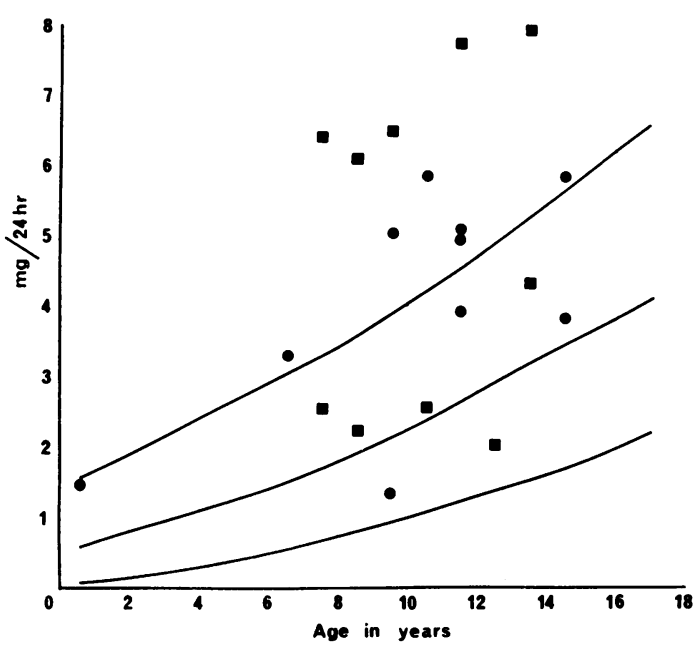

FIG. 2.-Excretion of $\alpha$-ketolic cortisol metabolites in obese children plotted against the mean $\pm 2 S D$ of values for normal children.

the $\alpha$-ketolic metabolites of cortisol to the 11deoxygenated-17-oxosteroids were compared in the obese children with those in the normal controls. They were not as a group significantly different.

(a) Obese children $6-10$ years $2 \cdot 4,11-17$ years $2 \cdot 2$; normal children $6-10$ years $2 \cdot 1,11-17$ years $1 \cdot 9$.

(b) Obese children $6-10$ years $11 \cdot 6,11-17$ years $8 \cdot 2$; normal children $6-10$ years $14 \cdot 4,11-17$ years $6 \cdot 0$.

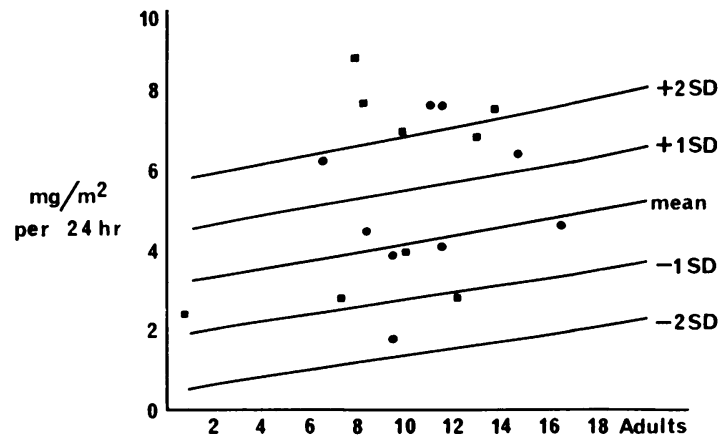

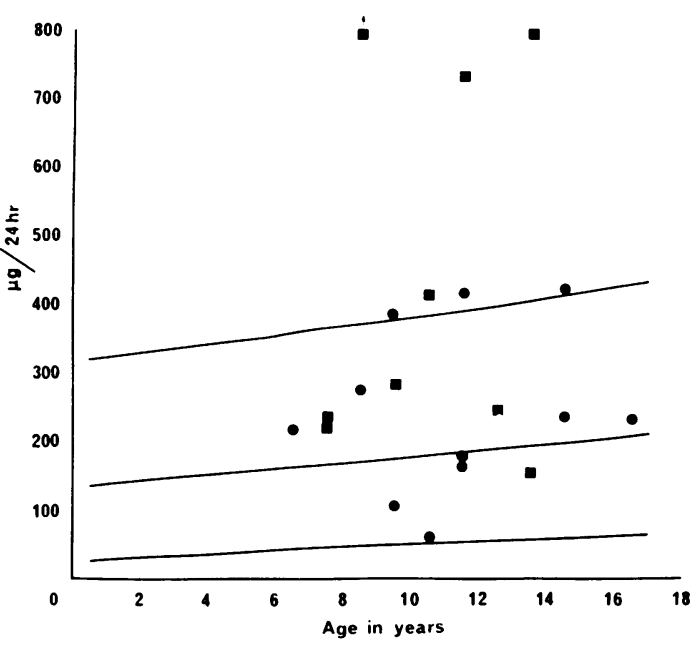

FIG. 4.-Excretion of $\alpha$-ketolic corticosterone metabolites in obese children corrected for surface area and body weight plotted against the mean $\pm 2 S D$ of values for normal children.

\section{Discussion}

It is recognized that some obese adults show an increased excretion of cortisol metabolites in their urine (Mlynaryk et al., 1962; Migeon et al., 1963; Prezio et al., 1964). In normal subjects the excretion of corticosteroids is directly related to body size (Norval and King, 1950; Borth, Linder, and Riondel, 1957; Savage et al., 1974) and though this has been stated to be true in obesity (Gordon,

Age in years

FIG. 3.-Excretion of 17-hydroxycorticosteroids in obese children corrected for surface area and body weight plotted against the mean $\pm 2 S D$ of values for normal children. 


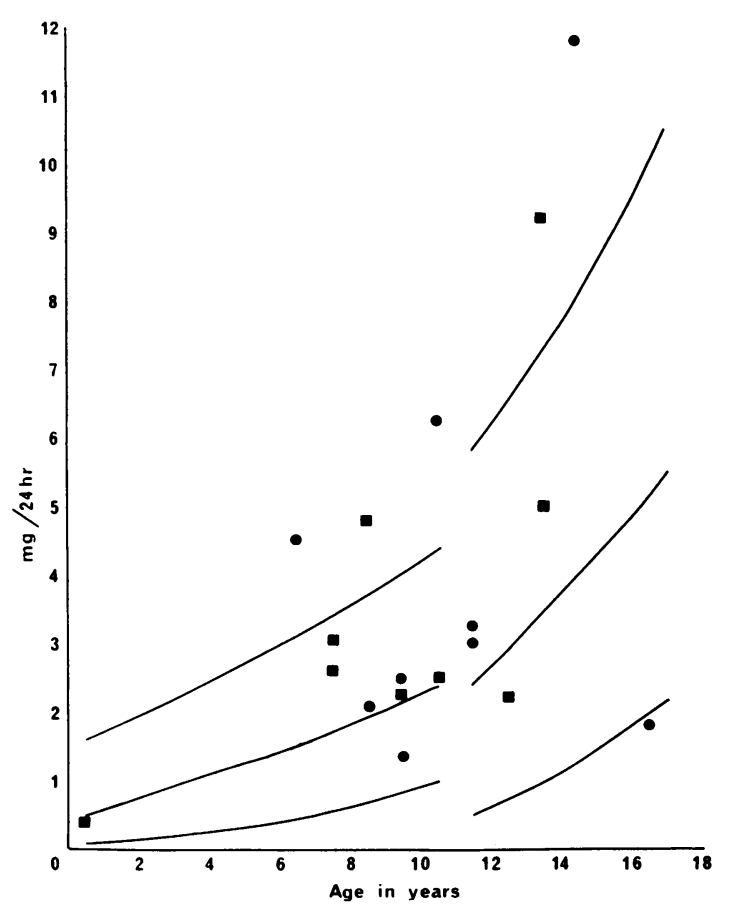

(a)

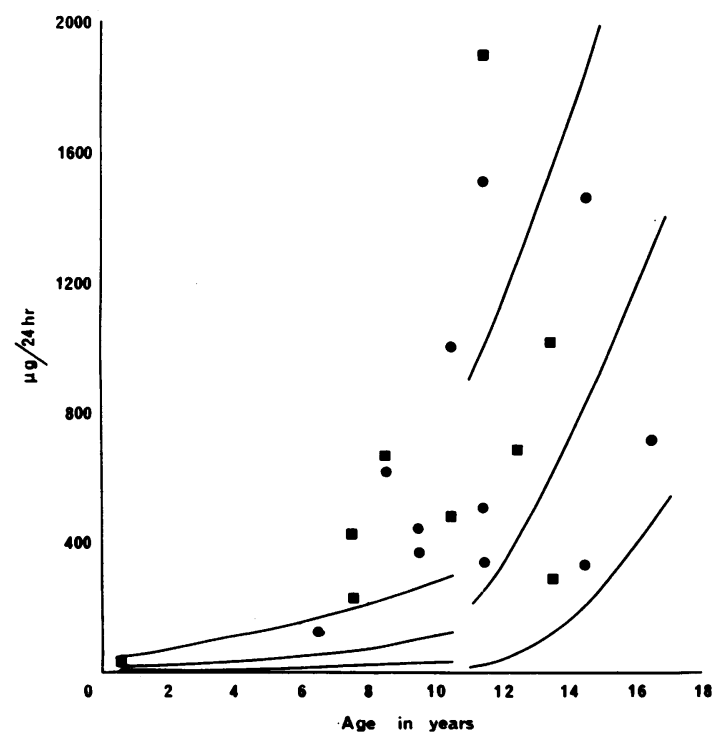

FIG. 5.-Excretion of (a) 17-oxosteroids and (b) 11deoxygenated-17-oxosteroids in obese children plotted against the mean $\pm 2 S D$ of values for normal children.
1970), it has not always been found (Migeon et al. 1963; Schteingart, Gregerman, and Conn, 1963). Furthermore, as some obese subjects show an increased response to ACTH, it has been presumed that in them there is a degree of adrenocortical hyperfunction (Dunkelman et al., 1964; Prezio et al., 1964).

In early reports on adrenocortical function in childhood obesity an increase in corticosteroid output was noted (Simpson, 1953; Gray et al., 1956; Cohen, 1958). Others have confirmed that the urinary $17 \mathrm{OHCS}$ excretion or cortisol secretion rate is increased in about $50 \%$ of obese children (Migeon et al., 1963; Jacobson et al., 1964; Van Herle et al., 1967; Garces et al., 1968, Hammar et al., 1972).

In the present study the excretion of the total 17 OHCS and $\alpha$-ketolic metabolites of cortisol in the obese children was significantly greater than the normal children and this difference persisted when the results were corrected for surface area. However, after correction for body weight only one obese child showed an excretion greater than 2 SDs above that of the normal child and, as a group, the obese children were not significantly different from them. This confirms other reports that the corticosteroid excretion in obese subjects is greater than that in normal persons when expressed in terms of surface area (Mlynaryk et al., 1962), but is not significantly different from them when corrected for body weight (Van Herle et al., 1967, Mlynaryk et al., 1962). However, it is apparent that in a few subjects there is increased cortisol secretion even when the results are expressed in this way (Garces et al., 1968; Schteingart et al., 1963; Dunkelman et al., 1964). With the exception of the increased $5 \alpha: 5 \beta$ ratios of allo-THF:THF no alteration in the excretory pattern of the individual cortisol metabolites was found in this study, confirming the observations of others that the changes found are basically quantitative (Schteingart et al., 1963; O'Connell et al., 1973).

The aetiology of the raised corticosteroid excretion found occasionally in obesity in excess of that expected for the increase in body weight has not been determined. Prezio and Jacobson both reported that those obese persons with adrenal hyperfunction had a relatively greater increase in lean body mass and suggested that like many other biological functions steroid secretion bore a relation to the lean body mass (Prezio et al., 1964; Jacobson et al., 1964). Similarly, Konishi (1964), examining the relationship of urinary 17 OHCS to creatinine excretion in obesity, also suggested that cortisol production varied with changes in muscle mass. However, it seems probable that other factors are 
also involved for though steroid excretion falls rapidly on a low calorie diet, there is initially no change in lean body mass (Jacobson et al., 1964).

In obesity, the plasma level of cortisol may be low (Szenas and Pattee, 1959; Mlynaryk et al., 1962; Van Herle et al., 1967), its half-life shortened (Mlynaryk et al., 1962; Dunkelman et al., 1964), and its production rate increased (Mlynaryk et al., 1962). In experimental obesity in man similar findings have been recorded (Sims and Horton, 1968; O'Connell et al., 1973). The reason for these changes is not fully understood but one of the controlling mechanisms of the plasma cortisol level, and therefore of adrenocortical activity, is the rate of cortisol metabolism by the liver. Schriefers (1967), in experiments on rats, has discussed the effect of food intake on the metabolism of steroids and has shown that, while a low calorie intake will cause retardation of $5 \alpha$ and $5 \beta$ dehydrogenase activity and hence of cortisol metabolism, an increased calorie intake will have the reverse effect. In fasted human subjects similar changes have been reported (Peterson, 1971). It is possible therefore that the increased calorie intake in obese persons might explain their increased turnover and excretion of cortisol.

The relation of cortisol to carbohydrate and lipid metabolism is complex, but it appears that cortisol has a permissive role rather than a primary regulatory function. It has been suggested that the increased turnover of cortisol in the liver could result in an increased activity of those liver enzymes associated with gluconeogenesis (Migeon et al., 1963). Furthermore, since cortisol has an inhibitory effect on the peripheral utilization of glucose (Cahill, 1971), its increased metabolite clearance in obesity will diminish this effect. Theoretically, therefore, these two factors, namely increased gluconeogenesis and a decreased inhibitory effect on the peripheral utilization of glucose will favour the synthesis and maintenance of adipose tissue stores.

After a glucose load, growth hormone output is lower than normal and insulin higher than normal in obese subjects. These hormone secretions are disordered in the same quantitative direction as those which occur after a meal in normal subjects and favour lipogenesis. Teleologically, it is realistic that eating should prime the body in such a way that excess food is stored as fat and the hormonal disturbances in obesity could perhaps be regarded as the persistence of a physiological event which is normally intermittent and transient.

In obesity the raised excretion of 17 OHCS and the cortisol secretion rate rapidly return to normal when the calorie intake is lowered (Schultz, Kerlow, and Ulstrom, 1964; Schachner et al., 1965; Garces et al., 1968). This suggests that the changes in corticosteroid metabolism in obese subjects are related as much to their overnutrition as to their increased weight. It is possible that those with high levels of corticosteroid excretion when corrected for body weight are those taking the greatest calorie intake relative to their body needs and may include those rapidly gaining weight at the time of study. The changes in corticosteroid secretion appear to be a consequence of the children's disturbed energy balance rather than the cause of the obesity, and though a few obese persons may have primary hypercorticoidism this is probably an exceptional situation.

The excretion of the corticosterone metabolites in the urine has not previously been reported in obesity. In the present study a few children had markedly raised levels of these metabolites and the obese group as a whole showed a significantly higher excretion than the normal controls. However, the excretion per $100 \mathrm{~kg}$ body weight did not differ from normal children and only one child showed evidence of hypersecretion of corticosterone when thus corrected. A raised excretion of aldosterone has been reported in obese subjects (Olivi et al., 1957; Scavo et al., 1967), though these authors did not relate their results to body weight. In obesity there is salt and water retention (Elsbach and Schwartz, 1961) and an increased corticosterone and aldosterone secretion may play some part in this metabolic disorder and thus favour the development of arterial hypertension.

The urinary excretion of the total 17-oxosteroids in obese adults may be raised (Simkin, 1961), normal (Gogate and Prunty, 1963), or even diminished (Poisnick and DiRaimondo, 1956). In a group of obese boys Van Herle et al. (1967) found raised levels of the 11-deoxygenated-17-oxosteroids, but other investigators have failed to show any increase in adrenal androgen excretion in children (Simpson, 1953; Gray et al., 1956; Jacobson et al., 1964; Hammar et al., 1972). In the present study the excretion of the 17-oxosteroids and the 11deoxygenated-17-oxosteroids by the obese children was significantly greater than that of the normal children. Concomitant with this was the increase in $5 \alpha: 5 \beta$ ratios of the various metabolites since $5 \alpha$ dehydrogenase activity in the liver is directly related to the level of circulating plasma androgens (Dorfman and Ungar, 1965). As the ratio of cortisol metabolites to the 11-deoxy-17-oxosteroids remained normal there was no discrepancy noted 
between the excretion of cortisol and androgens in the obese children.

Dehydroepiandrosterone (DHA) has been reported to be excreted in abnormally low amounts in the urine of obese persons (Sonka and Gregorová, 1963; Sonka et al., 1964). Dehydroepiandrosterone is a powerful inhibitor of glucose-6-phosphate dehydrogenase, the initial enzyme involved in the degradation of glucose by way of the pentose pathway (Tsutsui, Marks, and Reich, 1962). Glucose oxidation through this enzyme sequence is recognized as a major source of reduced nicotinamide-adenine dinucleotide phosphate (NADPH) which is required as a hydrogen donor for the reductive steps of lipogenesis. Theoretically, therefore, low DHA levels will favour fat formation. Lopez-S and Krehl (1967) have correlated the urinary excretion of DHA with the concentration of glucose-6-phosphate dehydrogenase in the erythrocytes and have shown that in obese subjects DHA excretion was inversely proportional to glucose-6-phosphate dehydrogenase levels. Weight reduction restored these figures to normal.

In the present study, dehydroepiandrosterone sulphate (DHAS) was not significantly different from the levels recorded in the control subjects, though androsterone and aetiocholanolone excretion was increased. However, DHA levels in prepubertal children are low and a reduction would be distinguished less easily than in adults. Though DHAS is not an inhibitor of glucose-6-phosphate dehydrogenase (Tsutsui et al., 1962), it does reflect the adrenocortical secretion of DHA. Its low concentration in blood and tissues contrasts with the massive influence which has been suggested on lipogenesis. Since the relatively low level of DHA appears to be corrected by weight loss, it seems unlikely that it in itself has any direct aetiological role in obesity.

In the sexually mature obese subjects the increased androgen secretion may reflect their increased muscle mass (Jacobson et al., 1964), since there is a correlation between adrenal androgen output and muscle width (Tanner and Gupta, 1968).

Obese children enter puberty at an earlier age than their peers (Wolff, 1955) and in the light of the data provided by Frisch and Revelle (1971) that there may be a direct relation between a critical body weight and the onset of puberty, the marked increase in adrenal androgen excretion in the prepubertal children aged 7-10 years in our series is of particular interest. Puberty is initiated by the neuroendocrine hypothalamus liberating increasing amounts of the releasing factor which stimulates and releases pituitary gonadotrophins. The events which lead up to these hormonal changes are, however, not clearly understood, but evidence suggests that the hypothalamus prepubertally develops a decreasing sensitivity to the inhibitory effect of circulating sex steroids and that this results in an increasing output of gonadotrophin releasing factor (Kulin, Grumbach, and Kaplan, 1969). Whether in humans the hypothalamus may mature early due to increased adrenal androgen excretion is not known, but experiments in rats have suggested that adrenal androgens may play a role in the induction of puberty (Rosenfield, 1972).

We are grateful to Professors J. L. Henderson and R. G. Mitchell for their interest in our research programme, to Mrs. Aileen Farquharson for technical assistance, to Mr. J. C. G. Pearson for statistical advice, and to Mrs. B. Forsyth for typing the script. The assays of the total 17-oxosteroids and 17-hydroxycorticosteroids were carried out in the steroid laboratory under the direction of Miss Margaret Browning. The work was supported by a grant from the Medical Research Council, London, and the Board of Management for Ninewells and Associated Hospitals.

\section{REFERENCES}

Albrink, M. J. (1968). Endocrine aspects of obesity. American Fournal of Clinical Nutrition, 21, 1395.

Borth, R., Linder, A., and Riondel, A. (1957). Urinary excretion of 17-hydroxycorticosteroids and 17-ketosteroids in healthy subjects, in relation to sex, age, body weight and height. Acta Endocrinologica, 25, 33.

Cahill, F. G. (1971). Action of adrenal cortical steroids on carbohydrate metabolism. In The Human Adrenal Cortex, p. 205. Ed. by N. P. Christy. Harper and Row, London and New York.

Cohen, H. (1958). 17-ketogenic steroid excretion in obese children before and after weight reduction. British Medical fournal, 1, 686.

Dorfman, R. I., and Ungar, F. (1965). Metabolism of Steroid Hormones, p. 549. Academic Press, New York.

Dunkelman, S. S., Fairhurst, B., Plager, J., and Waterhouse, C. (1964). Cortisol metabolism in obesity. Fournal of Clinical Endocrinology and Metabolism, 24, 832.

Elsbach, P., and Schwartz, I. L. (1961). Salt and water metabolism during weight reduction. Metabolism, 10, 595.

Frisch, R. E., and Revelle, R. (1971). Height and weight at menarche and a hypothesis of menarche. Archives of Disease in Childhood, 46, 695.

Garces, L. Y., Kenny, F. M., Drash, A., and Taylor, F. H. (1968). Cortisol secretion rate during fasting of obese adolescent subjects. Fournal of Clinical Endocrinology and Metabolism, 28, 1843.

Gogate, A. N., and Prunty, F. T. G. (1963). Adrenal cortical function in 'obesity with pink striae' in the young adult. fournal of Clinical Endocrinology and Metabolism, 23, 747.

Gordon, E. S. (1970). Metabolic aspects of obesity. Advances in Metabolic Disorders, 4, 229.

Gray, C. H., Lunnon, J. B., Pond, M. H., and Simpson, S. L. (1956). Steroid studies in normal and adipose children. Fournal of Clinical Endocrinology and Metabolism, 16, 473.

Hammar, S. L., Campbell, M. M., Campbell, V. A., Moores, N. L., Sareen, C., Gareis, F. J., and Lucas, B. (1972). An interdisciplinary study of adolescent obesity. Fournal of Pediatrics, $80,373$. 
Jacobson, G., Seltzer, C. C., Bondy, P. K., and Mayer, J. (1964). Importance of body characteristics in the excretion of 17ketosteroids and 17-ketogenic steroids in obesity. New England fournal of Medicine, 271, 651.

Konishi, F. (1964). The relationship of urinary 17-hydroxycorticosteroids to creatinine in obesity. Metabolism, 13, 847.

Kulin, H. E., Grumbach, M. M., and Kaplan, S. L. (1969). Changing sensitivity of the pubertal gonadal hypothalamic feedback mechanism in man. Science, 166, 1012.

Lopez-S, A., and Krehl, W. A. (1967). A possible interrelation between glucose-6-phosphate dehydrogenase and dehydroepiandrosterone in obesity. Lancet, $2,485$.

Migeon, C. J., Green, O. C., and Eckert, J. P. (1963). Study of adrenocortical function in obesity. Metabolism, 12, 718 .

Mlynaryk, P., Gillies, R. R., Murphy, B., and Pattee, C. J. (1962). Cortisol production rates in obesity. Fournal of Clinical Endocrinology and Metabolism, 22, 587.

Norval, M. A., and King, N. (1950). A biometric study of the excretion of corticosteroids in children in relation to age, height and weight. Biometrics, 6, 395.

O'Connell, M., Danforth, E., Horton, E. S., Salans, L., and Sims, E. A. H. (1973). Experimental obesity in man. III. Adrenocortical function. Fournal of Clinical Endocrinology and Metabolism, 36, 323.

Olivi, O., Ramenghi, M., Coppini, D., Montorsi, M., and Spada, A. (1957). L'eliminazione urinaria di aldosterone neil' obesità essenziale infantile. Minerva Medica, 48, 2543.

Peterson, R. E. (1971). Metabolism of adrenal cortical steroids. In The Human Adrenal Cortex, p. 87. Ed. by N. P. Christy. Harper and Row, New York.

Poisnick, J., and DiRaimondo, V. (1956). Adrenocortical function in obese women. Fournal of Clinical Endocrinology and Metabolism, 16, 957.

Prezio, J. A., Carreon, G., Clerkin, E., Meloni, C. R., Kyle, L. H., and Canary, J. J. (1964). Influence of body composition on adrenal function in obesity. Fournal of Clinical Endocrinology and Metabolism, 24, 481.

Rosenfield, R. L. (1972). Role of androgens in growth and development of the fetus, child and adolescent. Advances in Pediatrics, 19,171

Salans, L. B., and Wise, J. K. (1970). Metabolic studies of human obesity. Medical Clinics of North America, 54, 1533.

Savage, D. C. L., Forsyth, C. C., McCafferty, E., and Cameron, J. (1974). The excretion of individual adrenocortical steroids during normal childhood and adolescence. (Submitted for publication.)

Scavo, D., Iacobelli, A., Giovannini, C., and Cugini, P. (1967). Aspetti di funzione corticosurrenalica nelle obesità. Folia Endocrinologica, 20, 164.

Schachner, S. H., Wieland, R. G., Maynard, D. E., Kruger, F. A. and Hamwi, G. J. (1965). Alterations in adrenal cortical function in fasting obese subjects. Metabolism, 14, 1051.
Schriefers, H. (1967). Factors regulating the metabolism of steroids. Vitamins and Hormones, 25, 271.

Schteingart, D. E., Gregerman, R. I., and Conn, J. W. (1963). A comparison of the characteristics of increased adrenocortical function in obesity and in Cushing's syndrome. Metabolism, $12,484$.

Schultz, A. L., Kerlow, A., and Ulstrom, R. A. (1964). Effect of starvation on adrenal cortical function in obese subjects. fournal of Clinical Endocrinology and Metabolism, 24, 1253.

Simkin, B. (1961). Urinary 17-ketosteroid and 17-ketogenic steroid excretion in obese patients. New England fournal of Medicine, 264, 974.

Simpson, S. L. (1953). Pituitary-adrenal hyperfunction. Proceedings of the Royal Society of Medicine, 46, 39.

Sims, E. A. H., and Horton, E. S. (1968). Endocrine and metabolic adaptation to obesity and starvation. American fournal of Clinical Nutrition, 21, 1455.

Sonka, J., and Gregorová, I. (1963). Dehydroepiandrosteronnový prïstup k patogenesi obesity. Acta Universitatis Carolinae, $\mathbf{8}$, 89.

Sonka, J., Gregorová, I., Pav, J., and Skrha, F. (1964). Dehydroepiandrosterone in obese diabetics. Lancet, $2,44$.

Szenas, P., and Pattee, C. J. (1959). Studies of adrenocortical function in obesity. Fournal of Clinical Endocrinology and Metabolism, 19, 344.

Tanner, J. M., and Gupta, D. (1968). A longitudinal study of the urinary excretion of individual steroids in children from 8 to 12 years old. Fournal of Endocrinology, 41, 139.

Tanner, J. M., and Whitehouse, R. H. (1966). Printed for the University of London, Institute of Child Health and The Hospital for Sick Children, Great Ormond Street, by Joseph Collard \& Sons, 24 Litchfield Street, Charing Cross Road, London W.C.2.

Tanner, J. M., Whitehouse, R. H., and Healy, M. J. R. (1962). $A$ New System for Estimating Skeletal Maturity from the Hand and Wrist, with Standards Derived from a Study of 2,600 Healthy British Children. Centre International de l'Enfance, Paris.

Tsutsui, E. A., Marks, P. A., and Reich, P. (1962). Effect of dehydroepiandrosterone on glucose-6-phosphate dehydrogenase activity and reduced triphosphopyridine nucleotide formation in adrenal tissue. Fournal of Biological Chemistry, 237, 3009.

Van Herle, A., Steeno, O., Heyns, W., Hendrikx, A., and de Moor, P. (1967). Adrenocortical and gonadal function in fat adolescent boys. European fournal of Steroids, 2, 283.

Wolff, O. H. (1955). Obesity in childhood: study of birth weight, the height, and the onset of puberty. Quarterly fournal of Medicine, 24, 109.

Correspondence to Dr. D. C. L. Savage, Department of Child Health, Royal Hospital for Sick Children, Bristol BS2 8BJ. 